\title{
Ribosomal Alteration-Derived Signals for Cytokine Induction in Mucosal and Systemic Inflammation: Noncanonical Pathways by Ribosomal Inactivation
}

\author{
Yuseok Moon ${ }^{1,2,3}$ \\ ${ }^{1}$ Laboratory of Mucosal Exposome and Biomodulation, Department of Microbiology and Immunology, \\ Pusan National University School of Medicine, Yangsan 626-870, Republic of Korea \\ ${ }^{2}$ Immunoregulatory Therapeutics Group in Brain Busan 21 Project, Busan 609-735, Republic of Korea \\ ${ }^{3}$ Medical Research Institute, Pusan National University, Busan 609-735, Republic of Korea \\ Correspondence should be addressed to Yuseok Moon; moon@pnu.edu
}

Received 14 September 2013; Accepted 22 November 2013; Published 2 January 2014

Academic Editor: Eduardo López-Collazo

Copyright (c) 2014 Yuseok Moon. This is an open access article distributed under the Creative Commons Attribution License, which permits unrestricted use, distribution, and reproduction in any medium, provided the original work is properly cited.

\begin{abstract}
Ribosomal inactivation damages $28 \mathrm{~S}$ ribosomal RNA by interfering with its functioning during gene translation, leading to stress responses linked to a variety of inflammatory disease processes. Although the primary effect of ribosomal inactivation in cells is the functional inhibition of global protein synthesis, early responsive gene products including proinflammatory cytokines are exclusively induced by toxic stress in highly dividing tissues such as lymphoid tissue and epithelia. In the present study, ribosomal inactivation-related modulation of cytokine production was reviewed in leukocyte and epithelial pathogenesis models to characterize mechanistic evidence of ribosome-derived cytokine induction and its implications for potent therapeutic targets of mucosal and systemic inflammatory illness, particularly those triggered by organellar dysfunctions.
\end{abstract}

\section{Introduction}

As the functional organelle for protein synthesis, ribosomes bound to the endoplasmic reticulum (ER) perform complex surveillance of various pathologic stresses [1-3]. Ribosomal alteration by endogenous and external insults can trigger a variety of pathogenic processes, including inflammatory responses [4-6]. Ribosomal inactivation can be induced by a large family of ribonucleolytic proteins that cleave $28 \mathrm{~s}$ ribosomal RNA at single phosphodiester bonds within a universally conserved sequence known as the sarcin-ricin loop, which leads to the dysfunction of peptidyltransferase and subsequent global translational arrest $[7,8]$. These ribosomeinactivating proteins (RIPs) are enzymes isolated mostly from plants and some of RIPs such as ricins and shiga toxins are potent cytotoxic biological weapons causing tissue injuries and inflammatory diseases $[9,10]$. Similar ribosomal RNA injuries have been observed during nonprotein ribosomeinactivating stress triggered by physical and chemical insults such as ultraviolet (UV) irradiation, trichothecene mycotoxins (mostly cereal contaminants produced by molds such
Fusarium species), palytoxin (an intense vasoconstrictor produced by marine species including dinoflagellate Ostreopsis ovata), and anisomycin (an antibiotic produced by Streptomyces griseolus), which also interfere with peptidyltransferase activity by directly or indirectly modifying $28 \mathrm{~s}$ rRNA [11, 12]. The primary action of most ribosome-inactivating stress is the functional inhibition of global protein synthesis; therefore, highly dividing tissues such as lymphoid tissue and mucosal epithelium are the most susceptible targets of the stress [13-15]. Although acute high levels of toxic insults lead to sepsis-like symptoms including hemolytic uremic syndrome $[16,17]$, several epidemiological studies have suggested that there are also links between ribosome-inactivating stress and human mucosal epithelial illnesses ranging from acute mucosal inflammatory disease to chronic illness, including epithelial malignancy [18-20]. Ribosome-inactivating stress has been investigated in various experimental models as an etiological factor of inflammatory diseases such as ulcerative colitis and hemolytic uremic syndrome [17, 21, 22]. Moreover, upper airway inflammation such as intranasal neutrophilic 
rhinitis, which is characterized by mucus hypersecretion, atrophy, and exfoliation of transitional epithelium, is also triggered by some of ribosome-inactivating trichothecenes [23-26]. Among a variety of mediators of the ribosomal inactivation-associated pathogenesis, proinflammatory cytokines play key roles in both mucosal and systemic inflammatory responses to ribosome-inactivating stress [2730]. Although the primary outcome of the insulted cells is the global protein synthesis inhibition due to the ribosomal RNA cleavage and modification [31], the insult leads to some exceptional production of proteins such as cytokines important for cellular homeostasis as well as a variety of pathogenic processes involved in cell survival modulation, proliferation, and stress response $[32,33]$. The present review described the mechanistic patterns of exceptional cytokine upregulation during the ribosomal dysfunction at various levels of gene regulation, including transcriptional signaling activation triggered by organellar distress, posttranscriptional upregulation, and favorable posttranslational processing of cytokines. Investigations of the molecular patterns of cytokine induction by ribosomal inactivation will improve our understanding of typical stress-induced processes of inflammatory signals and provide new insight into therapeutic targets for ribosome-related inflammatory diseases.

\section{Organellar Sentinels for Cytokine Induction: Ribosome and ER}

Some surface signaling receptors are gate keepers against intracellular stresses. Ribosomal inactivation by factors such as UV irradiation increases phosphorylation of the cytoplasmic membrane receptor, epidermal growth factor receptor (EGFR), on tyrosine residues to above basal levels, leading to activation of protein kinase $\mathrm{B}(\mathrm{PKB} / \mathrm{Akt1})$ and downregulation of the Ras-extracellular signal-regulated kinase (ERK) signaling cascade [34]. Ribosome-inactivating palytoxin interacts with high affinity cell-surface receptors, including the $\mathrm{Na}^{+}, \mathrm{K}^{+}$-ATPase, or $\mathrm{Na}^{+} / \mathrm{H}^{+}$antiporter [35-37]. These ribosomal inactivation-linked surface receptors (EGFR and $\mathrm{Na}^{+}, \mathrm{K}^{+}$-ATPase) can also trigger their downstream kinase signaling pathways, leading to proinflammatory cytokine production [38, 39]. Although surface receptors may be activated by ribosomal inactivation, most signaling sentinels that respond to ribosome-inactivating stressors are associated with organelles themselves, including the ribosome and endoplasmic reticulum (ER).

2.1. Ribosomal RNA Cleavage and PKR-Linked Sentinel for Ribosome-Inactivating Stress. Early responses to ribosomeinactivating stress activate the ribosome-based scaffold signaling protein network, resulting in diverse biological patterns including apoptosis and cytokine induction [40-42]. In addition to the modification or cleavage of ribosomal RNA, a variety of ribosome-inactivating stresses lead to phosphorylation of serine 51 on the alpha subunit of eukaryotic translation initiation factor 2 (eIF2), leading to global translational arrest [31]. The $\alpha$ subunit of eIF2 in the ribosome-based scaffold protein complex is the target of different stress-related mammalian protein kinases including double-stranded RNA-dependent protein kinase R (PKR) and protein kinase RNA-like endoplasmic reticulum kinase (PERK). Ribosome-inactivating stressors trigger an eIF2 $\alpha$ kinase PKR which is recruited into ribosomal protein complex during cellular pathogenic stresses in response to the inflammatory stimulation $[41,43,44]$. PKR is an interferoninduced serine/threonine protein kinase activated by doublestranded RNA (dsRNA) [45] that plays important roles in the antiviral defense by interferon, particularly during cell growth control and differentiation [46, 47]. Mainly, dsRNA mediates PKR activation upon viral infection, which blocks the synthesis of new viral particle proteins [48]. Ribosomeinactivating stress is another inflammatory trigger known to activate PKR-linked signaling pathways in the ribosome $[41,49,50]$. Since activated PKR mediates proinflammatory chemokine induction in response to viral infection, it increases infiltration of inflammatory cells including neutrophils which promotes tissue injuries in response to viral infection [41, 51]. Proinflammatory chemokines such as MCP-1 and IL-8 induced by ribosomal inactivation thus exacerbated viral bronchopneumonia induced by respiratory reovirus infection [51]. Mechanistically, ribosomal inactivation damages the loops in the ribosome, which facilitates ribosomal binding to one or both dsRNA-binding domains of PKR and induces enzymatic activation [41]. While acute exposure to high levels of ribosomal stress, activated PKR plays important roles in activating stress responses like cell death via mitogen-activated protein kinases (MAPKs) such as p54, p46, and c-Jun N-terminal kinase 1 and 2 (JNK1/2) [50], milder exposure to ribosomal inactivation can trigger mucosal and systemic inflammation via the production of proinflammatory chemokines by epithelial and other immune-related cells [27, 29, 30, 52]. Low levels of ribosomal insults promote proinflammatory cytokine induction via a different set of MAPKs such as p38 [40, 41]. One upstream activator of p38 that responds to ribosomal stress is $\mathrm{PKR}$, which is critical to ribosomal recruitment of p38, its subsequent phosphorylation, and p38-mediated transcriptional activation of proinflammatory cytokines [40]. In response to ribosomal inactivation by deoxynivalenol, ribosome recruits the hematopoietic cell kinase that also activates p38 MAP kinase cascade in macrophages [40]. Therefore, ribosomal $40 \mathrm{~S}$ subunit serves as a scaffold for PKR and other recruited signaling molecules, facilitating MAPK mobilization and subsequent cytokine induction. However, more definite molecular mechanisms should be addressed to identify the link between ribosome-specific activation of PKR and ribosomal inactivation in future studies.

\subsection{ER Stress-Related Sentineling Signals for Cytokine Induc-} tion by Ribosomal Inactivation. Ribosomes that synthesize proteins become bound to ER membrane, after which the two organelles engage in crosstalk related to various stress signals and the protein synthesis process $[2,3]$. Activated ribosomal proteins thus may induce ER stress-related responses, which are attenuated by deletion of ribosomes in yeast and human 
cells such as monocyte-derived cells and epithelial cells $[2,3,53]$. ER-disrupting environmental and genetic factors cause accumulation of misfolded and unfolded proteins in the ER lumen, a condition termed ER stress. Ribosomal inactivation can also alter ER functions, and some chemical ribosomal inactivators such as trichothecenes, verotoxins, or ricin enhance unfolded protein responses that contribute to proinflammatory cytokine production and apoptosis-linked tissue injuries [54-56]. ER stress is positively associated with chronic proinflammatory diseases [57-59]. In particular, ER stress is a risk factor of inflammatory bowel diseases (IBDs) including Crohn's disease and UC, which are triggered by genetic or environmental factors such as smoking, stress, diet, and microbial components that can induce excessive inflammation [60-63]. Mechanistically, proinflammatory cytokines play central roles in mediating ER stress-linked inflammatory diseases [64-66]. Moreover, unlike canonical nuclear factor kappa $\mathrm{B}(\mathrm{NF}-\kappa \mathrm{B})$ activation, the upstream activator $\mathrm{I} \kappa \mathrm{B} \alpha$ kinase (IKK) is not activated during ER stress [66]. Instead, the level of basal IKK activity maintained via an ER stress sensor inositol-requiring ER-to-nucleus signal kinase 1 (IRE1) is essential to regulation of NF- $\kappa$ B activation. Phosphorylated eIF $2 \alpha$ by PERK in combination with IRE1 action then leads to repressed synthesis of $\mathrm{I} \kappa \mathrm{B} \alpha$ and subsequent maximum NF$\kappa \mathrm{B}$ activation during ER stress in monocyte-derived cells [66, 67]. Although macrophage NF- $\kappa \mathrm{B}$ is activated by ribosomal insults, epithelial NF- $\kappa \mathrm{B}$ expression and activity are strictly regulated to prevent overstimulation of proinflammatory responses following exposure to commensal bacteria $[68,69]$. However, suppressed NF- $\kappa \mathrm{B}$ in gut epithelial cells is not beneficial during pathogen infection since the production of many antibacterial mediators such as defensins is dependent on NF- $\kappa \mathrm{B}$ signaling pathways for their induction in gut barrier. In spite of NF- $\kappa \mathrm{B}$ suppression some of epithelial proinflammatory chemokines such as IL- 8 are upregulated by ribosomal inactivation $[27,70,71]$. This NF- $\kappa \mathrm{B}$-independent cytokine induction will be further explained in the next section.

Moreover, ribosomal inactivation can trigger the expression of ER stress-linked transcriptional regulators such as CCAAT/enhancer-binding protein homologous protein (CHOP), which can mediate toxic inflammatory responses in human intestinal mucosa, lung, and pancreas [72, 73]. Although CHOP is a key apoptotic signal inducer, it can also modulate different types of inflammatory responses. Specifically, CHOP is a dominant negative form of $\mathrm{C} / \mathrm{EBP}$ family members that lacks DNA binding activity and can form heterodimer complexes with other C/EBP members, thereby inhibiting their functions as transcription factors. Since C/EBP $\beta$ mediates expression of anti-inflammatory peroxisome proliferator-activated receptor gamma (PPAR $\gamma)$ by forming homodimers and binding to the PPAR $\gamma$ promoter $[74,75]$, CHOP-C/EBP $\beta$ complex thus interferes with basal PPAR $\gamma$ expression and facilitates NF- $\kappa \mathrm{B}$ activation by ER stress [76]. Overall, ribosomal inactivation-induced ER stress enhances proinflammatory cytokine production via NF- $\kappa \mathrm{B}$ activation in monocyte-derived cells, which can be also facilitated by $\mathrm{CHOP}$-mediated regulation of anti-inflammatory
$\operatorname{PPAR} \gamma$. By contrast, ribosomal inactivation may suppress epithelial NF- $\kappa \mathrm{B}$ expression and activity while some of epithelial proinflammatory chemokines are enhanced in NF$\kappa \mathrm{B}$-independent ways.

\section{NF- $\kappa$ B-Independent Transcriptional Regulation of Cytokine Induction}

Once activated by early sentinels from ribosomal recruitment of signaling mediators or the provoked ER stress sentinels, the downstream MAPK cascade accelerates the induction of proinflammatory cytokines through activation of transcription factors such as NF- $\kappa \mathrm{B}$, activating protein 1 (AP1), CCAAT enhancer binding protein (C/EBP), cyclic AMP response element binding protein (CREB), and early growth response 1 (EGR-1) gene product [27, 33, 77-79]. Ribosomal inactivation activates NF- $\kappa$ B-linked proinflammatory signals for cytokine induction in monocyte-derived cells, while extended exposure to the toxic stress can suppress the signals in epithelia as commented [80, 81]. Moreover, induction of epithelial proinflammatory cytokines by ribosomal inactivation occurs independently of the NF- $\kappa \mathrm{B}$ signaling pathway $[27,28]$. Instead of NF- $\kappa$ B, EGR-1 can be involved in proinflammatory chemokine gene expression in ribosomal inactivation-insulted intestinal epithelial cells. Ambivalent roles of epithelial EGR-1 were recently addressed in response to mucosal ribosomal stress [68]. While EGR-1 positively mediates epithelial chemokine induction by ribosomal inactivation, EGR-1 also contributes to negative regulation of proinflammatory NF- $\kappa \mathrm{B}$ signaling via PPAR $\gamma$ induction in intestinal epithelial cells. EGR-1 is known to specifically bind and transactivate PPAR $\gamma$ promoter $[82,83]$ although it can also be involved in inhibition of PPAR $\gamma$ gene expression in some cell types [84]. Ribosomal inactivation disrupts the balance between PPAR $\gamma$ and NF- $\kappa \mathrm{B}$-linked signaling in the mucosal epithelia by enhancing EGR-1 gene expression and subsequently PPAR $\gamma$ levels, leading to greater suppression of proinflammatory NF- $\kappa$ B signaling in response to infectious agents including endotoxins [68]. Clinical investigations demonstrated that the commensal microflora can enhance the expression of PPAR $\gamma$ that is impaired in ulcerative colitis (UC) patients, particularly in the enterocytes [8587]. Since epithelial PPAR $\gamma$ plays protective roles against the colonic inflammatory responses to both commensal and pathogenic bacteria [88-90], its attenuation by ribosomal insults would be detrimental as implicated in UC patients. Although PPAR $\gamma$ generally attenuates epithelial inflammatory responses by triggering nuclear export of p65 protein in complex with PPAR $\gamma$ [91], it can also regulate proinflammatory cytokine production via NF- $\kappa \mathrm{B}$-independent activation of signaling mediators such as protein kinase $\mathrm{C}$ alpha, which induces cellular desensitization to proinflammatory stimulation in monocyte-derived cells [92]. Overall, ribosomal inactivation triggers chemokine gene induction through NF- $\kappa \mathrm{B}$ or alternate proinflammatory transcription factors including EGR-1, while negatively regulating PPAR $\gamma$ directed anti-inflammatory actions. 


\section{Posttranscriptional Regulation}

In addition to transcriptional regulation, posttranscriptional modifications such as mRNA stabilization may lead to cytokine superinduction via ribosomal inactivation in leukocytes and gut epithelial cells $[69,93,94]$. Moreover, epithelial ER stress that can be triggered by ribosomal inactivation also enhances cytokine mRNA stability [95]. In response to ER stress, eukaryotic cells selectively shut down the global protein translation via eIF $2 \alpha$ phosphorylation, which results in a limited availability of the eIF2-GTP-tRNA ${ }^{\text {Met }}$ complex [96]. However, mRNA of some early stress responsive genes is rapidly recruited from translating ribosomes into stress granules (SGs) as untranslated form $[95,97]$. Independently of eIF $2 \alpha$ phosphorylation, blocking of ribosome recruitment also induces stress granule formation by interfering with eIF4B activity, an RNA helicase required for the ribosome recruitment phase of translation initiation $[98,99]$. Therefore, disruption of ribosomal integrity as an alternate pathway would induce the formation of SGs without regard to stressinduced $\mathrm{eIF} 2 \alpha$ phosphorylation. The temporal storage in stress granules provides mRNA with shelter from degradation and maintain silenced mRNAs to resume protein translation upon stress release. The untranslated mRNAs in SGs under stress are protected via SG-recruited mRNAstabilizing proteins such as HuR/Elav-like RNA binding protein 1 (ELAVL1) that positively regulates the stability of mRNA transcripts containing AU-rich elements (AREs), including those for proinflammatory cytokines [100-102]. $\mathrm{HuR}$ protein binds to AREs in the $3^{\prime}$ untranslated region ( $3^{\prime}$ UTR) of target mRNA molecules in the nucleus and then translocates into the cytoplasm for translation. Cytosolic translocation of the HuR protein is also initiated by mucosal ribosome-inactivating stress and ultimately stabilizes cytokine mRNA in the cytoplasm and SGs [71, 93]. As an $\mathrm{HuR}$ modulator, $\mathrm{CHOP}$ plays key roles in maintenance of the mRNA stability of cytokine genes in response to ribosomeinactivating stress [71]. Similar to ER stress, ribosomeinactivating stress induces CHOP expression, which also suppresses PPAR $\gamma$ expression as indicated in Section 2. As a target of CHOP induced by ribosomal inactivation, PPAR $\gamma$ is not involved in epithelial chemokine regulation at the transcriptional level. Instead, $\mathrm{CHOP}$ is a positive regulator of cytokine mRNA transcript stability that occurs via $\mathrm{HuR}$ protein $[71,76]$. In response to mucosal ribosomal inactivation, enhanced mucosal PPAR $\gamma$ regulates epithelial chemokine gene induction, which is posttranscriptionally modulated by HuR independently of NF- $\kappa \mathrm{B}$-linked signals $[71,103]$. Mechanistically, induction of CHOP by ribosomal inactivation enhances the cytosolic translocation of $\mathrm{HuR}$ protein by suppressing PPAR $\gamma$ expression. Because PPAR $\gamma$ inhibits the cytosolic translocation of $\mathrm{HuR}$, suppression of PPAR $\gamma$ by CHOP protein facilitates HuR movement into the cytoplasm and subsequent cytokine mRNA stabilization [71]. Ribosome inactivation-triggered translocation of $\mathrm{HuR}$ protein also enhances expression of activating transcription factor 3 (ATF3), which plays a central role in the regulation of proinflammatory NF- $\kappa \mathrm{B}$ signals in human gut epithelial cells [102]. Therefore, HuR contributes to cytokine superinduction by ribosome-inactivating stress while retarding NF$\kappa \mathrm{B}$ activation via ATF3. Further studies are needed to assess the effects of altered PPAR $\gamma$ on the stability of chemokine transcripts in addition to the regulatory action of PPAR $\gamma$ on transcriptional activity of chemokine genes in response to mucosal ribosomal inactivation. Taken together, ribosomal inactivation leads to chemokine superinduction via mRNA stabilization by RNA-binding proteins such as HuR whose cytosolic translocation is facilitated by CHOP protein. Moreover, HuR can mediate ATF3 superinduction as well, leading to suppression of NF- $\kappa \mathrm{B}$ signals in enterocytes.

\section{Posttranslational Processing of Proinflammatory Cytokines and Cytokine Receptors}

5.1. Roles of Inflammasomes in Cytokine Processing. Following transcriptional induction, some proinflammatory cytokines such as interleukin $1 \beta$ (IL-1 $\beta$ ) and interleukin 18 (IL-18) undergo maturation triggered by the inflammasome-linked sentinel [104-106]. Ribosome-inactivating stress also triggers some inflammasome-linked processes that promote the maturation of inflammatory cytokines in monocyte-derived cells [107-109]. Ricin, a potent ribosomal toxin, leads to acute lung injury and symptoms resembling acute respiratory distress syndrome via the IL- $1 \beta$-activated signaling pathway in alveolar macrophages [110]. Mechanistically, the nod-like receptor (NLR) family member, NLRP3, stimulates IL-1 $\beta$ processing via NLRP3 inflammasome, which is triggered by ribosome-inactivating stress in pulmonary macrophages $[107,108]$. Although the detailed molecular modes are still unknown, ribosomal inactivation may mediate a drop in cellular potassium, leading to protein translation and subsequent activation of the NLRP3 inflammasome [108]. A recent study suggested that, as another mechanism of inflammasome activation by ribosomal inactivation, the activation of p38 MAPK by ribosome-inactivating stress triggers formation of a pyrin inflammasome complex with ASC: apoptosisassociated speck-like protein containing a caspase recruitment domain and procaspase-1, leading to ASC oligomerization, caspase- 1 activation, and pro-IL- $1 \beta$ processing in macrophages [109]. In both cases, ribosomal inactivation is considered to provoke latent inflammatory storms via inflammasome activation in the monocyte-derived cells.

\subsection{Ribosomal Inactivation-Triggered Ectodomain Shedding of} Cytokine Receptor. Ribosomal inactivation stimulates MAP kinase signaling via direct modulation of a broad spectrum of physiological stimuli including appropriate growth factors and cytokines $[10,32,111]$. Activated MAP kinase triggers phosphorylation of TNF- $\alpha$-converting enzyme (TACE), which is also known as a disintegrin and cell-surface metalloproteinase 17 (ADAM17), which is then translocated to the cell surface for its action. TACE-dependent ectodomain shedding of cell-surface proteins is increased by ERK and p38 MAP kinase, which phosphorylate threonine 735 in the cytoplasmic tail of TACE $[112,113]$. Ligands of the epidermal 


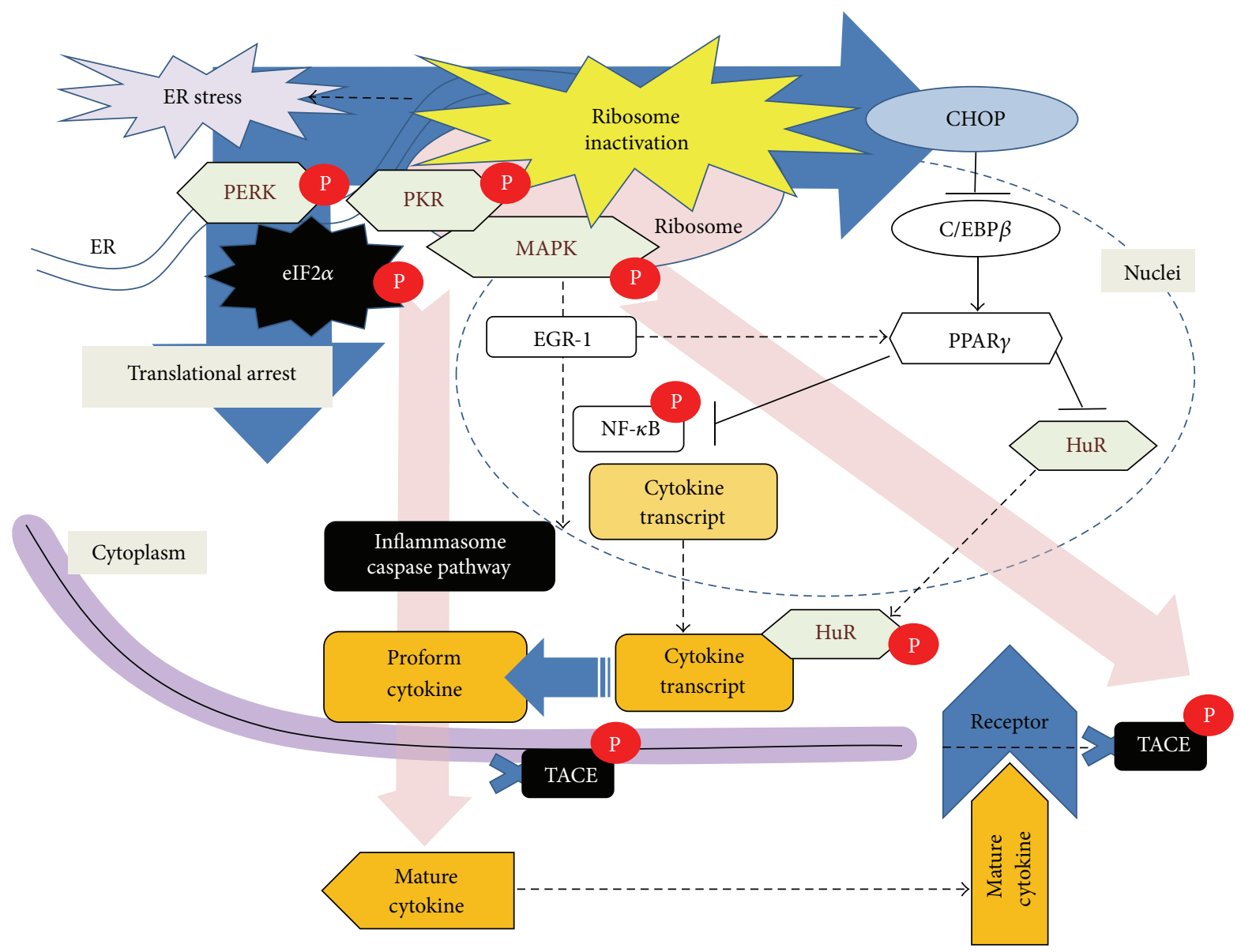

FIGURE 1: A putative diagram of ribosomal stress-derived signaling networks for cytokine induction.

growth factor receptor (EGF) need to be cleaved by TACE and shed as soluble proteins in order to become systemically available and many proinflammatory cytokines or receptors of the tumor necrosis factor alpha (TNF $\alpha$ ) family are also cleaved by TACE [113-115]. Consistent with these findings, ribosomal inactivation activates TACE-mediated ectodomain shedding of TNF receptor 1 via activated MAP kinases in pneumocytes $[116,117]$. In this case, ribosomal inactivation attenuated cellular responses to proinflammatory cytokines via TACEmediated shedding of cytokine receptor, which regulates the storm of proinflammatory cytokines in the body that occurs under the ribosomal-inactivating stress. However, TACE is also needed for the generation of soluble TNF $\alpha$, an important therapeutic target of inflammatory diseases such as arthritis, sepsis and colitis and thus the inhibition of TACE leads to protection from the diseases in animals [118] although many physiologic activities of TACE make blockade of this enzyme problematic [119]. Since TACE-associated cytokine regulation could be thus beneficial or detrimental, more careful investigations are needed for the ultimate actions of the ribosomal inactivation in the TACE-related pathogenesis.

\section{Conclusion}

Although the primary effects of ribosomal inactivation on cells are linked to global protein synthesis, some early responsive gene products including proinflammatory cytokines are exclusively enhanced in lymphoid tissue and epithelia. Although surface receptors triggering cytokine induction are activated by some ribosomal inactivation, most primary responses originate from the ribosome and ER (Figure 1). The ribosomal subunit serves as a scaffold for PKR, while other signaling mediators help promote their activation, which then facilitates MAPK mobilization and subsequent cytokine induction. Ribosomal inactivationinduced ER stress also can mediate proinflammatory cytokine production via NF- $\kappa \mathrm{B}$ activation, which is facilitated by CHOP-mediated regulation of anti-inflammatory $\operatorname{PPAR} \gamma$. In addition to NF- $\kappa \mathrm{B}$-linked signals, cytokine expressions are transcriptionally promoted by alternate proinflammatory transcription factors such as EGR-1 but paradoxically EGR-1 enhances PPAR $\gamma$ expression, which suppresses proinflammatory NF- $\kappa \mathrm{B}$ signaling in gut epithelial cells. In addition to transcriptional regulation, posttranscriptional modifications such as mRNA stabilization contribute to cytokine superinduction via various RNA-binding stabilizers such as HuR for stabilization of mRNA transcripts with cytokine transcript AREs. Moreover, cytokine mRNA stability is enhanced by CHOP protein, which facilitates cytosolic translocation of HuR by limiting PPAR $\gamma$ expression in cells under ribosome-inactivating stress. Cytokine protein 
processing is another critical regulation by ribosomal insult. Some proforms of cytokines such as IL-1 $\beta$ and IL-18 are cleaved to mature active forms by inflammasome-triggered caspases, which are also activated by ribosomal inactivation in macrophages. However, since ribosomal inactivation causes shedding of the ectodomain of several cytokine receptors via MAPK-activated cell-surface metalloproteinase TACE, additional information is needed to understand whether the ribosomal inactivation would attenuate or exacerbate the stress-associated inflammatory diseases.

\section{Conflict of Interests}

The author declares that there is no conflict of interests regarding the publication of this paper.

\section{Acknowledgments}

This work was supported by the Basic Science Research Program through the National Research Foundation of Korea, funded by Ministry of Education, Science, and Technology Grant (NRF-2012R1A1A2005837) and a Grant from the Korean Health Technology Research and Development Project, Ministry of Health and Welfare, Republic of Korea, (HI13C0259).

\section{References}

[1] C. Deisenroth and Y. Zhang, "Ribosome biogenesis surveillance: probing the ribosomal protein-Mdm2-p53 pathway," Oncogene, vol. 29, no. 30, pp. 4253-4260, 2010.

[2] K. K. Steffen, M. A. McCormick, K. M. Pham et al., "Ribosome deficiency protects against ER stress in Saccharomyces cerevisiae," Genetics, vol. 191, no. 1, pp. 107-118, 2012.

[3] F. Zhang, R. B. Hamanaka, E. Bobrovnikova-Marjon et al., "Ribosomal stress couples the unfolded protein response to p53dependent cell cycle arrest," Journal of Biological Chemistry, vol. 281, no. 40, pp. 30036-30045, 2006.

[4] F. Wan, A. Weaver, X. Gao, M. Bern, P. R. Hardwidge, and M. J. Lenardo, "IKK $\beta 2$ phosphorylation regulates RPS3 nuclear translocation and NF- $\kappa$ B function during infection with Escherichia coli strain O157:H7, Nature Immunology, vol. 12, no. 4, pp. 335-344, 2011.

[5] E. M. Wier, J. Neighoff, X. Sun, K. Fu, and F. Wan, "Identification of an N-terminal truncation of the NF-kappaB p 65 subunit that specifically modulates ribosomal protein S3-dependent NFkappaB gene expression," The Journal of Biological Chemistry, vol. 287, pp. 43019-43029, 2012.

[6] H. J. Yang, H. Youn, K. M. Seong, Y. W. Jin, J. Kim, and B. Youn, "Phosphorylation of ribosomal protein S3 and antiapoptotic TRAF2 protein mediates radioresistance in non-small cell lung cancer cells," The Journal of Biological Chemistry, vol. 288, pp. 2965-2975, 2013.

[7] J. Lacadena, E. Álvarez-García, N. Carreras-Sangrà et al., "Fungal ribotoxins: molecular dissection of a family of natural killers," FEMS Microbiology Reviews, vol. 31, no. 2, pp. 212-237, 2007.

[8] T. B. Ng, J. H. Wong, and H. Wang, "Recent progress in research on ribosome inactivating proteins," Current Protein and Peptide Science, vol. 11, no. 1, pp. 37-53, 2010.
[9] Y. Moon, "Mucosal injuries due to ribosome-inactivating stress and the compensatory responses of the intestinal epithelial barrier," Toxins, vol. 3, no. 10, pp. 1263-1277, 2011.

[10] Y. Moon, "Cellular alterations of mucosal integrity by ribotoxins: mechanistic implications of environmentally-linked epithelial inflammatory diseases," Toxicon, vol. 59, no. 1, pp. 192-204, 2012.

[11] M. S. Iordanov, D. Pribnow, J. L. Magun, T.-H. Dinh, J. A. Pearson, and B. E. Magun, "Ultraviolet radiation triggers the ribotoxic stress response in mammalian cells," Journal of Biological Chemistry, vol. 273, no. 25, pp. 15794-15803, 1998.

[12] M. Li and J. J. Pestka, "Comparative induction of $28 \mathrm{~S}$ ribosomal RNA cleavage by ricin and the trichothecenes deoxynivalenol and T-2 toxin in the macrophage," Toxicological Sciences, vol. 105, no. 1, pp. 67-78, 2008.

[13] P. Bunyard, M. Handley, G. Pollara et al., "Ribotoxic stress activates p38 and JNK kinases and modulates the antigenpresenting activity of dendritic cells," Molecular Immunology, vol. 39, no. 13, pp. 815-827, 2003.

[14] C. Instanes and G. Hetland, "Deoxynivalenol (DON) is toxic to human colonic, lung and monocytic cell lines, but does not increase the IgE response in a mouse model for allergy," Toxicology, vol. 204, no. 1, pp. 13-21, 2004.

[15] W. E. Smith, A. V. Kane, S. T. Campbell, D. W. K. Acheson, B. H. Cochran, and C. M. Thorpe, "Shiga toxin 1 triggers a ribotoxic stress response leading to p38 and JNK activation and induction of apoptosis in intestinal epithelial cells," Infection and Immunity, vol. 71, no. 3, pp. 1497-1504, 2003.

[16] S. A. Braune, D. Wichmann, M.C. von Heinz et al., "Clinical features of critically ill patients with Shiga toxin-induced hemolytic uremic syndrome," Critical Care Medicine, vol. 41, no. 7, pp. 1702-1710, 2013.

[17] V. Korcheva, J. Wong, C. Corless, M. Iordanov, and B. Magun, "Administration of ricin induces a severe inflammatory response via nonredundant stimulation of ERK, JNK, and p38 MAPK and provides a mouse model of hemolytic uremic syndrome," American Journal of Pathology, vol. 166, no. 1, pp. 323-339, 2005.

[18] Y. Luo, T. Yoshizawa, and T. Katayama, "Comparative study on the natural occurrence of Fusarium mycotoxins (trichothecenes and zearalenone) in corn and wheat from high- and low-risk areas for human esophageal cancer in China," Applied and Environmental Microbiology, vol. 56, no. 12, pp. 3723-3726, 1990.

[19] F.-Q. Li, Y.-W. Li, X.-Y. Luo, and T. Yoshizawa, "Fusarium toxins in wheat from an area in Henan Province, PR China, with a previous human red mould intoxication episode," Food Additives and Contaminants, vol. 19, no. 2, pp. 163-167, 2002.

[20] R. V. Bhat, S. R. Beedu, Y. Ramakrishna, and K. L. Munshi, "Outbreak of trichothecene mycotoxicosis associated with consumption of mould-damaged wheat production in Kashmir Valley, India," The Lancet, vol. 1, pp. 35-37, 1989.

[21] J. M. Yoder, R. U. Aslam, and N. J. Mantis, "Evidence for widespread epithelial damage and coincident production of monocyte chemotactic protein 1 in a murine model of intestinal ricin intoxication," Infection and Immunity, vol. 75, no. 4, pp. 1745-1750, 2007.

[22] C. M. Thorpe, B. P. Hurley, L. L. Lincicome, M. S. Jacewicz, G. T. Keusch, and D. W. K. Acheson, "Shiga toxins stimulate secretion of interleukin-8 from intestinal epithelial cells," Infection and Immunity, vol. 67, no. 11, pp. 5985-5993, 1999. 
[23] C. J. Amuzie, Z. Islam, J. K. Kim, J.-H. Seo, and J. J. Pestka, "Kinetics of satratoxin G tissue distribution and excretion following intranasal exposure in the mouse," Toxicological Sciences, vol. 116, no. 2, pp. 433-440, 2010.

[24] S. A. Carey, C. G. Plopper, D. M. Hyde, Z. Islam, J. J. Pestka, and J. R. Harkema, "Satratoxin-G from the black mold Stachybotrys chartarum induces rhinitis and apoptosis of olfactory sensory neurons in the nasal airways of rhesus monkeys," Toxicologic Pathology, vol. 40, pp. 887-898, 2012.

[25] K. N. Corps, Z. Islam, J. J. Pestka, and J. R. Harkema, "Neurotoxic, inflammatory, and mucosecretory responses in the nasal airways of mice repeatedly exposed to the macrocyclic trichothecene mycotoxin roridin A: dose-response and persistence of injury," Toxicologic Pathology, vol. 38, no. 3, pp. 429-451, 2010.

[26] Z. Islam, C. J. Amuzie, J. R. Harkema, and J. J. Pestka, "Neurotoxicity and inflammation in the nasal airways of mice exposed to the Macrocyclic trichothecene mycotoxin roridin A: kinetics and potentiation by bacterial lipopolysaccharide coexposure," Toxicological Sciences, vol. 98, no. 2, pp. 526-541, 2007.

[27] Y. Moon, H. Yang, and S.-H. Park, "Hypo-responsiveness of interleukin-8 production in human embryonic epithelial intestine 407 cells independent of NF- $\kappa$ B pathway: new lessons from endotoxin and ribotoxic deoxynivalenol," Toxicology and Applied Pharmacology, vol. 231, no. 1, pp. 94-102, 2008.

[28] S.-H. Park, H. J. Choi, H. Yang, K. H. Do, J. Kim, and Y. Moon, "Repression of peroxisome proliferator-activated receptor $\gamma$ by mucosal ribotoxic insult-activated CCAAT/enhancer-binding protein homologous protein," Journal of Immunology, vol. 185, no. 9, pp. 5522-5530, 2010.

[29] H.-R. Zhou, J. R. Harkema, D. Yan, and J. J. Pestka, "Amplified proinflammatory cytokine expression and toxicity in mice coexposed to lipopolysaccharide and the trichothecene vomitoxin (deoxynivalenol)," Journal of Toxicology and Environmental Health A, vol. 57, no. 2, pp. 115-136, 1999.

[30] H.-R. Zhou, Q. Jia, and J. J. Pestka, "Ribotoxic stress response to the trichothecene deoxynivalenol in the macrophage involves the Src family kinase Hck," Toxicological Sciences, vol. 85, no. 2, pp. 916-926, 2005.

[31] T. Rzymski and A. L. Harris, "The unfolded protein response and integrated stress response to anoxia," Clinical Cancer Research, vol. 13, no. 9, pp. 2537-2540, 2007.

[32] J. D. Laskin, D. E. Heck, and D. L. Laskin, "The ribotoxic stress response as a potential mechanism for MAP kinase activation in xenobiotic toxicity," Toxicological Sciences, vol. 69, no. 2, pp. 289-291, 2002.

[33] V. I. Shifrin and P. Anderson, "Trichothecene mycotoxins trigger a ribotoxic stress response that activates c-Jun N-terminal kinase and p38 mitogen-activated protein kinase and induces apoptosis," Journal of Biological Chemistry, vol. 274, no. 20, pp. 13985-13992, 1999.

[34] M. S. Iordanov, R. J. Choi, O. P. Ryabinina, T.-H. Dinh, R. K. Bright, and B. E. Magun, "The UV (ribotoxic) stress response of human keratinocytes involves the unexpected uncoupling of the Ras-extracellular signal-regulated kinase signaling cascade from the activated epidermal growth factor receptor," Molecular and Cellular Biology, vol. 22, no. 15, pp. 5380-5394, 2002.

[35] F. A. Braz, J. S. Cruz, A. C. Faria-Campos, and S. V. Campos, "Probabilistic model checking analysis of palytoxineffects on cell energy reactions of the $\mathrm{Na}^{+} / \mathrm{K}^{+}$-ATPase," IEEE Transactions on Computational Biology and Bioinformatics. In press.
[36] S. Ficarra, A. Russo, F. Stefanizzi et al., "Palytoxin induces functional changes of anion transport in red blood cells: metabolic impact," Journal of Membrane Biology, vol. 242, no. 1, pp. 31-39, 2011.

[37] E. V. Wattenberg, "Palytoxin: exploiting a novel skin tumor promoter to explore signal transduction and carcinogenesis," American Journal of Physiology: Cell Physiology, vol. 292, no. 1, pp. C24-C32, 2007.

[38] R. Crinelli et al., "Palytoxin and an Ostreopsis toxin extract increase the levels of mRNAs encoding inflammation-related proteins in human macrophages via p38 MAPK and NFkappaB," PLoS ONE, vol. 7, Article ID e38139, 2012.

[39] T. B. El-Abaseri, B. Hammiller, S. K. Repertinger, and L. A. Hansen, "The epidermal growth factor receptor increases cytokine production and cutaneous inflammation in response to ultraviolet irradiation," ISRN Dermatology, vol. 2013, Article ID 848705, 11 pages, 2013.

[40] H. Bae, J. S. Gray, M. Li, L. Vines, J. Kim, and J. J. Pestka, "Hematopoietic cell kinase associates with the $40 \mathrm{~S}$ ribosomal subunit and mediates the ribotoxic stress response to deoxynivalenol in mononuclear phagocytes," Toxicological Sciences, vol. 115 , no. 2, pp. 444-452, 2010.

[41] J. S. Gray, H. K. Bae, J. C. B. Li, A. S. Lau, and J. J. Pestka, "Double-stranded RNA-activated protein kinase mediates induction of interleukin-8 expression by deoxynivalenol, shiga toxin 1, and ricin in monocytes," Toxicological Sciences, vol. 105, no. 2, pp. 322-330, 2008.

[42] K. He, H. R. Zhou, and J. J. Pestka, "Mechanisms for ribotoxininduced ribosomal RNA cleavage," Toxicology and Applied Pharmacology, vol. 265, no. 1, pp. 10-18, 2012.

[43] J. Deng, H. P. Harding, B. Raught et al., "Activation of gen2 in uv-irradiated cells inhibits translation," Current Biology, vol. 12, no. 15, pp. 1279-1286, 2002.

[44] S.-Y. Lee, M.-S. Lee, R. P. Cherla, and V. L. Tesh, "Shiga toxin 1 induces apoptosis through the endoplasmic reticulum stress response in human monocytic cells," Cellular Microbiology, vol. 10, no. 3, pp. 770-780, 2008.

[45] O. Donzé, J. Deng, J. Curran, R. Sladek, D. Picard, and N. Sonenberg, "The protein kinase PKR: a molecular clock that sequentially activates survival and death programs," The EMBO Journal, vol. 23, no. 3, pp. 564-571, 2004.

[46] L. Malmgaard, "Induction and regulation of IFNs during viral infections," Journal of Interferon and Cytokine Research, vol. 24, no. 8, pp. 439-454, 2004.

[47] A. Pindel and A. Sadler, "The role of protein kinase R in the interferon response," Journal of Interferon and Cytokine Research, vol. 31, no. 1, pp. 59-70, 2011.

[48] E. Meurs, K. Chong, J. Galabru et al., "Molecular cloning and characterization of the human double-stranded RNA-activated protein kinase induced by interferon," Cell, vol. 62, no. 2, pp. 379-390, 1990

[49] K. He, H. R. Zhou, and J. J. Pestka, "Targets and intracellular signaling mechanisms for deoxynivalenol-induced ribosomal RNA cleavage," Toxicological Sciences, vol. 127, pp. 382-390, 2012.

[50] H.-R. Zhou, A. S. Lau, and J. J. Pestka, "Role of double-stranded RNA-activated protein kinase R (PKR) in deoxynivalenolinduced ribotoxic stress response," Toxicological Sciences, vol. 74, no. 2, pp. 335-344, 2003.

[51] M. Li, J. R. Harkema, C. F. Cuff, and J. J. Pestka, "Deoxynivalenol exacerbates viral bronchopneumonia induced by respiratory 
reovirus infection," Toxicological Sciences, vol. 95, no. 2, pp. 412426, 2007.

[52] S.-H. Park, H. J. Choi, H. Yang, K. H. Do, J. Kim, and Y. Moon, "Repression of peroxisome proliferator-activated receptor $\gamma$ by mucosal ribotoxic insult-activated CCAAT/enhancer-binding protein homologous protein," Journal of Immunology, vol. 185, no. 9, pp. 5522-5530, 2010.

[53] H. Yang, S. H. Park, H. J. Choi et al., "Mechanism-based alternative monitoring of endoplasmic reticulum stress by 8 -ketotrichothecene mycotoxins using human intestinal epithelial cell line," Toxicology Letters, vol. 198, no. 3, pp. 317-323, 2010.

[54] B. A. Parikh, A. Tortora, X.-P. Li, and N. E. Tumer, "Ricin inhibits activation of the unfolded protein response by preventing splicing of the HAC1 mRNA," Journal of Biological Chemistry, vol. 283, no. 10, pp. 6145-6153, 2008.

[55] Y. Shi, K. Porter, N. Parameswaran, H. K. Bae, and J. J. Pestka, "Role of GRP78/BiP degradation and ER stress in deoxynivalenol-induced interleukin-6 upregulation in the macrophage," Toxicological Sciences, vol. 109, no. 2, pp. 247-255, 2009.

[56] V. L. Tesh, "Activation of cell stress response pathways by Shiga toxins," Cellular Microbiology, vol. 14, no. 1, pp. 1-9, 2012.

[57] P. J. Kahle and C. Haass, "How does parkin ligate ubiquitin to Parkinson's disease? First in molecular medicine review series," EMBO Reports, vol. 5, no. 7, pp. 681-685, 2004.

[58] E. Araki, S. Oyadomari, and M. Mori, "Endoplasmic reticulum stress and diabetes mellitus," Internal Medicine, vol. 42, no. 1, pp. 7-14, 2003.

[59] W. Lin, H. P. Harding, D. Ron, and B. Popko, "Endoplasmic reticulum stress modulates the response of myelinating oligodendrocytes to the immune cytokine interferon- $\gamma$," Journal of Cell Biology, vol. 169, no. 4, pp. 603-612, 2005.

[60] S. Lesage, H. Zouali, J.-P. Cézard et al., "CARD15/NOD2 mutational analysis and genotype-phenotype correlation in 612 patients with inflammatory bowel disease," American Journal of Human Genetics, vol. 70, no. 4, pp. 845-857, 2002.

[61] B. Katschinski, R. F. A. Logan, M. Edmond, and M. J. S. Langman, "Smoking and sugar intake are separate but interactive risk factors in Crohn's disease," Gut, vol. 29, no. 9, pp. 1202-1206, 1988.

[62] S. M. Collins, "Stress and the gastrointestinal tract IV. Modulation of intestinal inflammation by stress: basic mechanisms and clinical relevance," American Journal of Physiology: Gastrointestinal and Liver Physiology, vol. 280, no. 3, pp. G315-G318, 2001.

[63] M. Campieri and P. Gionchetti, "Probiotics in inflammatory bowel disease: new insight to pathogenesis or a possible therapeutic alternative?" Gastroenterology, vol. 116, no. 5, pp. 1246$1249,1999$.

[64] B. Baban, J. Y. Liu, and M. S. Mozaffari, "Endoplasmic reticulum stress response and inflammatory cytokines in type 2 diabetic nephropathy: role of indoleamine 2,3-dioxygenase and programmed death-1," Experimental and Molecular Pathology, vol. 94, pp. 343-351, 2012.

[65] M. Kitamura, "Control of NF-kappaB and inflammation by the unfolded protein response," International Reviews of Immunology, vol. 30, pp. 4-15, 2011.

[66] A. B. Tam, E. L. Mercado, A. Hoffmann, and M. Niwa, "ER stress activates NF-kappaB by integrating functions of basal IKK activity, IRE1 and PERK," PLOS ONE, vol. 7, Article ID e45078, 2012.
[67] A. D. Garg, A. Kaczmarek, O. Krysko, P. Vandenabeele, D. V. Krysko, and P. Agostinis, "ER stress-induced inflammation: does it aid or impede disease progression?" Trends in Molecular Medicine, vol. 18, pp. 589-598, 2012.

[68] K. H. Do, H. J. Choi, J. Kim et al., "Ambivalent roles of early growth response 1 in inflammatory signaling following ribosomal insult in human enterocytes," Biochemical Pharmacology, vol. 84, pp. 513-521, 2012.

[69] S. H. Park, K. H. Do, H. J. Choi et al., "Novel regulatory action of ribosomal inactivation on epithelial Nod2-linked proinflammatory signals in two convergent ATF3-associated pathways," The Journal of Immunology, vol. 191, pp. 5170-5181, 2013.

[70] Y. Moon, H. Yang, and S. H. Lee, "Modulation of early growth response gene 1 and interleukin- 8 expression by ribotoxin deoxynivalenol (vomitoxin) via ERK1/2 in human epithelial intestine 407 cells," Biochemical and Biophysical Research Communications, vol. 362, no. 2, pp. 256-262, 2007.

[71] S.-H. Park, H. J. Choi, H. Yang, K. H. Do, J. Kim, and Y. Moon, "Repression of peroxisome proliferator-activated receptor $\gamma$ by mucosal ribotoxic insult-activated CCAAT/enhancer-binding protein homologous protein," Journal of Immunology, vol. 185, no. 9, pp. 5522-5530, 2010.

[72] M. Endo, M. Mori, S. Akira, and T. Gotoh, "C/EBP homologous protein $(\mathrm{CHOP})$ is crucial for the induction of caspase-11 and the pathogenesis of lipopolysaccharide-induced inflammation," Journal of Immunology, vol. 176, no. 10, pp. 6245-6253, 2006.

[73] T. Namba, K.-I. Tanaka, Y. Ito et al., "Positive role of CCAAT/enhancer-binding protein homologous protein, a transcription factor involved in the endoplasmic reticulum stress response in the development of colitis," American Journal of Pathology, vol. 174, no. 5, pp. 1786-1798, 2009.

[74] Z. Wu, Y. Xie, N. L. R. Bucher, and S. R. Farmer, "Conditional ectopic expression of C/EBP $\beta$ in NIH-3T3 cells induces PPAR $\gamma$ and stimulates adipogenesis," Genes and Development, vol. 9, no. 19, pp. 2350-2363, 1995.

[75] Y. Zhu, C. Qi, J. R. Korenberg et al., "Structural organization of mouse peroxisome proliferator-activated receptor $\gamma(\mathrm{mPPAR} \gamma)$ gene: alternative promoter use and different splicing yield two mPPAR $y$ isoforms," Proceedings of the National Academy of Sciences of the United States of America, vol. 92, no. 17, pp. 79217925, 1995.

[76] S.-H. Park, H. J. Choi, H. Yang et al., "Endoplasmic reticulum stress-activated C/EBP homologous protein enhances nuclear factor- $\kappa \mathrm{B}$ signals via repression of peroxisome proliferatoractivated receptor," Journal of Biological Chemistry, vol. 285, no. 46, pp. 35330-35339, 2010.

[77] D. M. Jandhyala, T. J. Rogers, A. Kane, A. W. Paton, J. C. Paton, and C. M. Thorpe, "Shiga toxin 2 and flagellin from Shigatoxigenic Escherichia coli superinduce interleukin-8 through synergistic effects on host stress-activated protein kinase activation," Infection and Immunity, vol. 78, no. 7, pp. 2984-2994, 2010.

[78] R. Sakiri, B. Ramegowda, and V. L. Tesh, "Shiga toxin type 1 activates tumor necrosis factor- $\alpha$ gene transcription and nuclear translocation of the transcriptional activators nuclear factor- $\kappa \mathrm{B}$ and activator protein-1," Blood, vol. 92, no. 2, pp. 558$566,1998$.

[79] J. Van De Walle, A. During, N. Piront, O. Toussaint, Y.-J. Schneider, and Y. Larondelle, "Physio-pathological parameters affect the activation of inflammatory pathways by deoxynivalenol in 
Caco-2 cells," Toxicology in Vitro, vol. 24, no. 7, pp. 1890-1898, 2010.

[80] N. Hauf and T. Chakraborty, "Suppression of NF- $\kappa$ B activation and proinflammatory cytokine expression by Shiga toxinproducing Escherichia coli," Journal of Immunology, vol. 170, no. 4, pp. 2074-2082, 2003.

[81] H. Sugimoto, T. Kataoka, M. Igarashi, M. Hamada, T. Takeuchi, and K. Nagai, "E-73, an acetoxyl analogue of cycloheximide, blocks the tumor necrosis factor-induced NF- $\kappa \mathrm{B}$ signaling pathway," Biochemical and Biophysical Research Communications, vol. 277, no. 2, pp. 330-333, 2000.

[82] M. Fu, J. Zhang, Y. Lin, X. Zhu, M. U. Ehrengruber, and Y. E. Chen, "Early growth response factor-1 is a critical transcriptional mediator of peroxisome proliferator-activated receptor$\gamma 1$ gene expression in human aortic smooth muscle cells," Journal of Biological Chemistry, vol. 277, no. 30, pp. 2680826814, 2002.

[83] M. Okada, S. F. Yan, and D. J. Pinsky, "Peroxisome proliferatoractivated receptor- $\gamma$ (PPAR- $\gamma$ ) activation suppresses ischemic induction of Egr-1 and its inflammatory gene targets," The FASEB Journal, vol. 16, no. 14, pp. 1861-1868, 2002.

[84] Y. Zhou, X. Jia, M. Zhou, and J. Liu, "Egr-1 is involved in the inhibitory effect of leptin on PPAR $\gamma$ expression in hepatic stellate cell in vitro," Life Sciences, vol. 84, no. 15-16, pp. 544-551, 2009.

[85] M. Adachi, R. Kurotani, K. Morimura et al., "Peroxisome proliferator activated receptor $\gamma$ in colonic epithelial cells protects against experimental inflammatory bowel disease," Gut, vol. 55, no. 8, pp. 1104-1113, 2006.

[86] L. Dubuquoy, E. Å Jansson, S. Deeb et al., "Impaired expression of peroxisome proliferator-activated receptor $\gamma$ in ulcerative colitis," Gastroenterology, vol. 124, no. 5, pp. 1265-1276, 2003.

[87] L. Dubuquoy, C. Rousseaux, X. Thuru et al., "PPAR $\gamma$ as a new therapeutic target in inflammatory bowel diseases," Gut, vol. 55, no. 9, pp. 1341-1349, 2006.

[88] C. Jiang, A. T. Ting, and B. Seed, "PPAR- $\gamma$ agonists inhibit production of monocyte inflammatory cytokines," Nature, vol. 391, no. 6662, pp. 82-86, 1998.

[89] M. Ricote, A. C. Li, T. M. Willson, C. J. Kelly, and C. K. Glass, "The peroxisome proliferator-activated receptor- $\gamma$ is a negative regulator of macrophage activation," Nature, vol. 391, no. 6662, pp. 79-82, 1998.

[90] Y. Barak, M. C. Nelson, E. S. Ong et al., "PPAR $\gamma$ is required for placental, cardiac, and adipose tissue development," Molecular Cell, vol. 4, no. 4, pp. 585-595, 1999.

[91] D. Kelly, J. I. Campbell, T. P. King et al., “Commensal anaerobic gut bacteria attenuate inflammation by regulating nuclearcytoplasmic shutting of PPAR- $\gamma$ and ReIA," Nature Immunology, vol. 5, no. 1, pp. 104-112, 2004.

[92] A. von Knethen, M. Soller, N. Tzieply et al., "PPAR $\gamma 1$ attenuates cytosol to membrane translocation of PKC $\alpha$ to desensitize monocytes/macrophages," Journal of Cell Biology, vol. 176, no. 5, pp. 681-694, 2007.

[93] H. J. Choi, H. Yang, S. H. Park, and Y. Moon, "HuR/ELAVL1 RNA binding protein modulates interleukin-8 induction by muco-active ribotoxin deoxynivalenol," Toxicology and Applied Pharmacology, vol. 240, no. 1, pp. 46-54, 2009.

[94] Y.-J. Chung, H.-R. Zhou, and J. J. Pestka, “Transcriptional and posttranscriptional roles for p38 mitogen-activated protein kinase in upregulation of TNF- $\alpha$ expression by deoxynivalenol (vomitoxin)," Toxicology and Applied Pharmacology, vol. 193, no. 2, pp. 188-201, 2003.
[95] S. H. Park, H. J. Choi, H. Yang et al., "Two in-and-out modulation strategies for endoplasmic reticulum stress-linked gene expression of pro-apoptotic macrophage-inhibitory cytokine 1 ," The Journal of Biological Chemistry, vol. 287, no. 24, pp. 1984119855, 2012.

[96] P. Anderson and N. Kedersha, "Stressful initiations," Journal of Cell Science, vol. 115, no. 16, pp. 3227-3234, 2002.

[97] S. Hu, E. C. Claud, M. W. Musch, and E. B. Chang, "Stress granule formation mediates the inhibition of colonic Hsp70 translation by interferon- $\gamma$ and tumor necrosis factor- $\alpha$," American Journal of Physiology: Gastrointestinal and Liver Physiology, vol. 298, no. 5, pp. G795-G796, 2010.

[98] R. Mazroui, R. Sukarieh, M.-E. Bordeleau et al., "Inhibition of ribosome recruitment induces stress granule formation independently of eukaryotic initiation factor $2 \alpha$ phosphorylation," Molecular Biology of the Cell, vol. 17, no. 10, pp. 4212-4219, 2006.

[99] S. Mokas, J. R. Mills, C. Garreau et al., "Uncoupling stress granule assembly and translation initiation inhibition," Molecular Biology of the Cell, vol. 20, no. 11, pp. 2673-2683, 2009.

[100] J. Fan, F. T. Ishmael, X. Fang et al., "Chemokine transcripts as targets of the RNA-binding protein HuR in human airway epithelium," Journal of Immunology, vol. 186, no. 4, pp. 24822494, 2011.

[101] S. Feng, W. Chen, D. Cao et al., "Involvement of $\mathrm{Na}^{+}, \mathrm{K}^{+}-$ ATPase and its inhibitors in HuR-mediated cytokine mRNA stabilization in lung epithelial cells," Cellular and Molecular Life Sciences, vol. 68, no. 1, pp. 109-124, 2011.

[102] S. H. Park, H. J. Choi, K. H. Do, H. Yang, J. Kim, and Y. Moon, "Chronic Nod2 stimulation potentiates activating transcription factor 3 and paradoxical superinduction of epithelial proinflammatory chemokines by mucoactive ribotoxic stressors via RNAbinding protein human antigen R," Toxicological Sciences, vol. 125, no. 1, pp. 116-125, 2012.

[103] E.-Y. Choi, Z.-Y. Park, E.-J. Choi et al., "Transcriptional regulation of IL- 8 by iron chelator in human epithelial cells is independent from NF- $\kappa$ B but involves ERK1/2- and p38 kinasedependent activation of AP-1," Journal of Cellular Biochemistry, vol. 102, no. 6, pp. 1442-1457, 2007.

[104] L. Agostini, F. Martinon, K. Burns, M. F. McDermott, P. N. Hawkins, and J. Tschopp, "NALP3 forms an IL-1 $\beta$-processing inflammasome with increased activity in Muckle-Wells autoinflammatory disorder," Immunity, vol. 20, no. 3, pp. 319-325, 2004.

[105] F. Martinon, K. Burns, and J. Tschopp, “The Inflammasome: a molecular platform triggering activation of inflammatory caspases and processing of proIL- $\beta$," Molecular Cell, vol. 10, no. 2, pp. 417-426, 2002.

[106] S. M. Srinivasula, J.-L. Poyet, M. Razmara, P. Datta, Z. Zhang, and E. S. Alnemri, "The PYRIN-CARD protein ASC is an activating adaptor for caspase-1," Journal of Biological Chemistry, vol. 277, no. 24, pp. 21119-21122, 2002.

[107] M. Lindauer, J. Wong, and B. Magun, "Ricin toxin activates the NALP3 inflammasome," Toxins, vol. 2, no. 6, pp. 1500-1514, 2010.

[108] M. L. Vyleta, J. Wong, and B. E. Magun, "Suppression of ribosomal function triggers innate immune signaling through activation of the NLRP3 inflammasome," PLoS ONE, vol. 7, Article ID e36044, 2012.

[109] J. W. Yu, A. Farias, I. Hwang, T. Fernandes-Alnemri, and E. S. Alnemri, "Ribotoxic stress through p38 mitogen-activated protein kinase activates in vitro the human pyrin inflammasome," 
The Journal of Biological Chemistry, vol. 288, pp. 11378-11383, 2013.

[110] M. L. Lindauer, J. Wong, Y. Iwakura, and B. E. Magun, "Pulmonary inflammation triggered by ricin toxin requires macrophages and IL-1 signaling," Journal of Immunology, vol. 183, no. 2, pp. 1419-1426, 2009.

[111] D. M. Jandhyala, C. M. Thorpe, and B. Magun, "Ricin and Shiga toxins: effects on host cell Signal transduction," Current Topics in Microbiology and Immunology, vol. 357, pp. 41-65, 2012.

[112] E. Díaz-Rodríguez, J. C. Montero, A. Esparís-Ogando, L. Yuste, and A. Pandiella, "Extracellular signal-regulated kinase phosphorylates tumor necrosis factor $\alpha$-converting enzyme at threonine 735: a potential role in regulated shedding," Molecular Biology of the Cell, vol. 13, no. 6, pp. 2031-2044, 2002.

[113] P. Xu, J. Liu, M. Sakaki-Yumoto, and R. Derynck, "TACE activation by MAPK-mediated regulation of cell surface dimerization and TIMP3 association," Science Signaling, vol. 5, article ra34, 2012.

[114] J. C. Montero, L. Yuste, E. Díaz-Rodríguez, A. Esparís-Ogando, and A. Pandiella, "Mitogen-activated protein kinase-dependent and -independent routes control shedding of transmembrane growth factors through multiple secretases," Biochemical Journal, vol. 363, no. 2, pp. 211-221, 2002.

[115] A. J. Scott, K. P. O’Dea, D. O'Callaghan et al., "Reactive oxygen species and p38 mitogen-activated protein kinase mediate tumor necrosis factor $\alpha$-converting enzyme (TACE/ADAM-17) activation in primary human monocytes," Journal of Biological Chemistry, vol. 286, no. 41, pp. 35466-35476, 2011.

[116] S. Hirano and T. Kataoka, "Deoxynivalenol induces ectodomain shedding of TNF receptor 1 and thereby inhibits the TNF-alphainduced NF-kappaB signaling pathway," European Journal of Pharmacology, vol. 701, pp. 144-151, 2013.

[117] Y. Yamada, S. Taketani, H. Osada, and T. Kataoka, "Cytotrienin A, a translation inhibitor that induces ectodomain shedding of TNF receptor 1 via activation of ERK and p38 MAP kinase," European Journal of Pharmacology, vol. 667, no. 1-3, pp. 113-119, 2011.

[118] C. Becker-Pauly and S. Rose-John, "TNFalpha cleavage beyond TACE/ADAM17: matrix metalloproteinase 13 is a potential therapeutic target in sepsis and colitis," EMBO Molecular Medicine, vol. 5, pp. 902-904, 2013.

[119] S. Rose-John, "ADAM17, shedding, TACE as therapeutic targets," Pharmacological Research, vol. 71, pp. 19-22, 2013. 


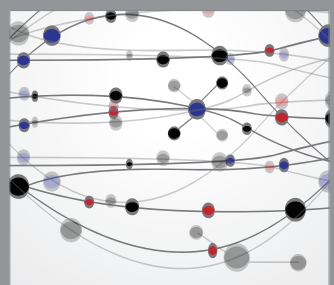

The Scientific World Journal
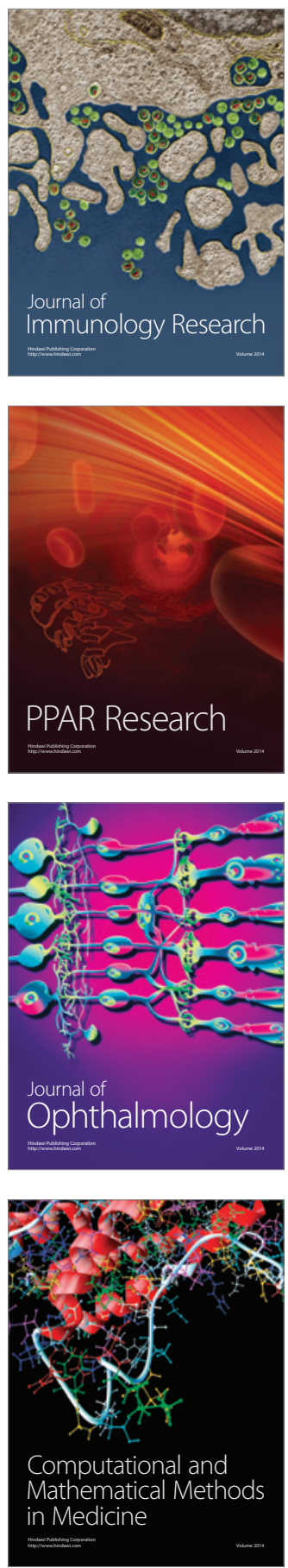

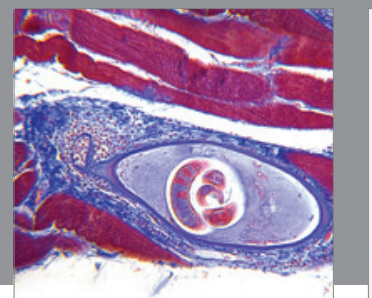

Gastroenterology

Research and Practice
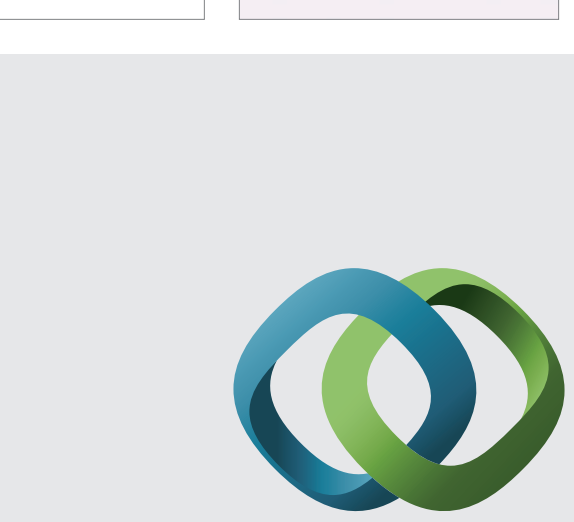

\section{Hindawi}

Submit your manuscripts at

http://www.hindawi.com
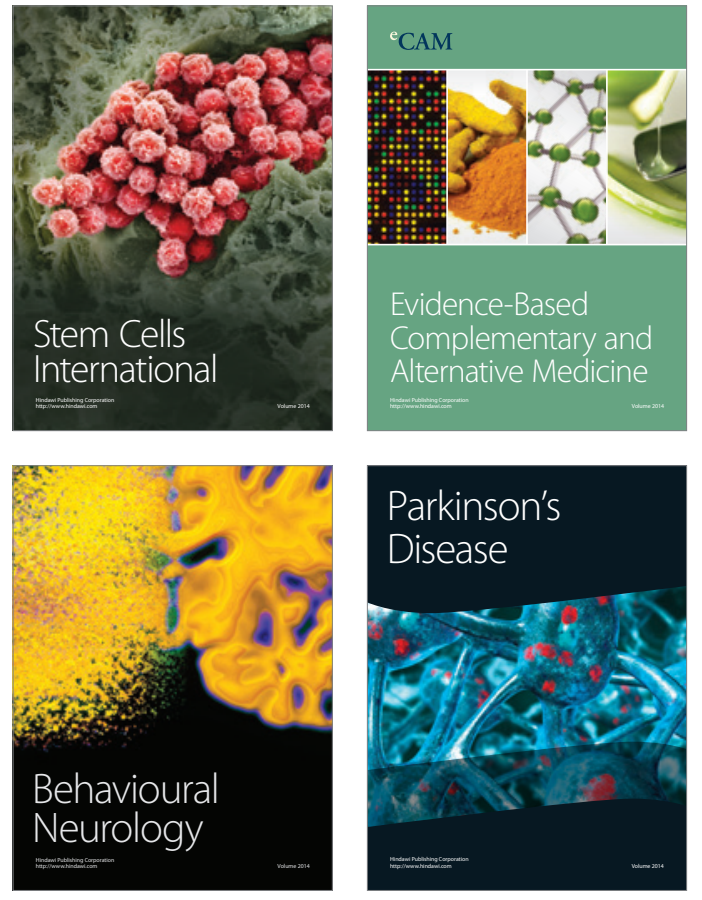
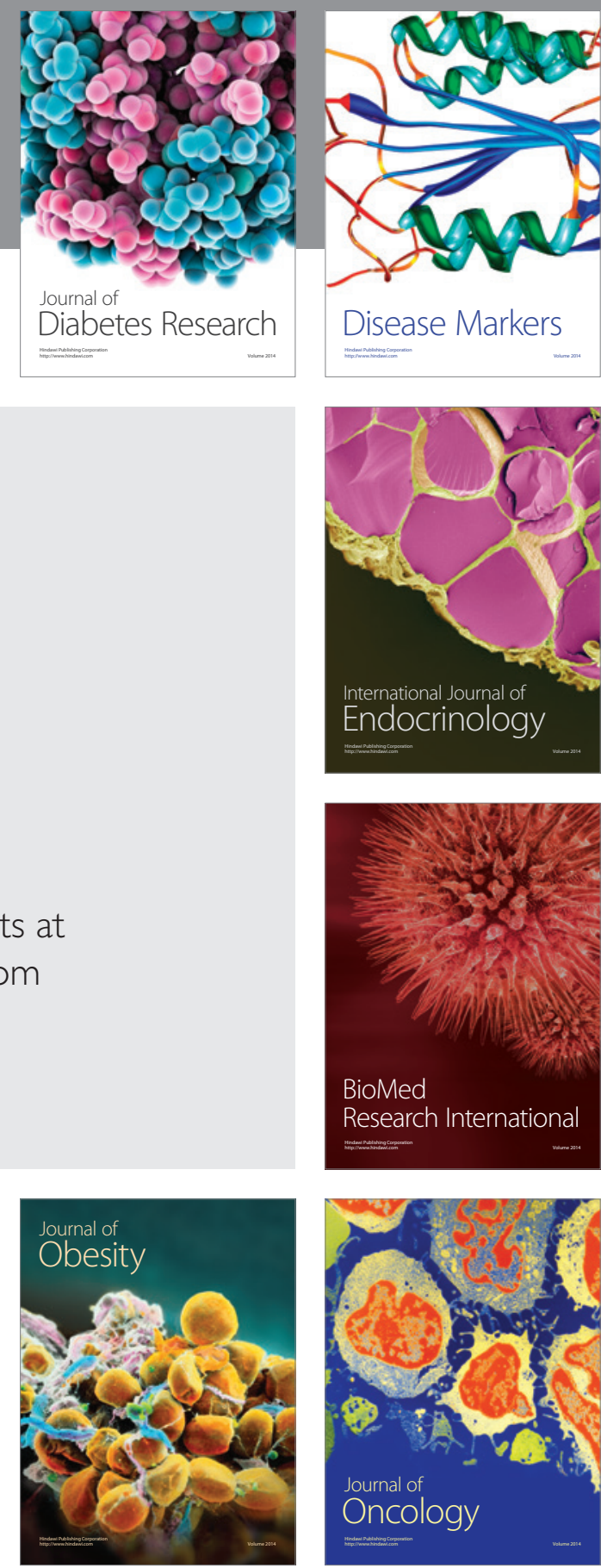

Disease Markers
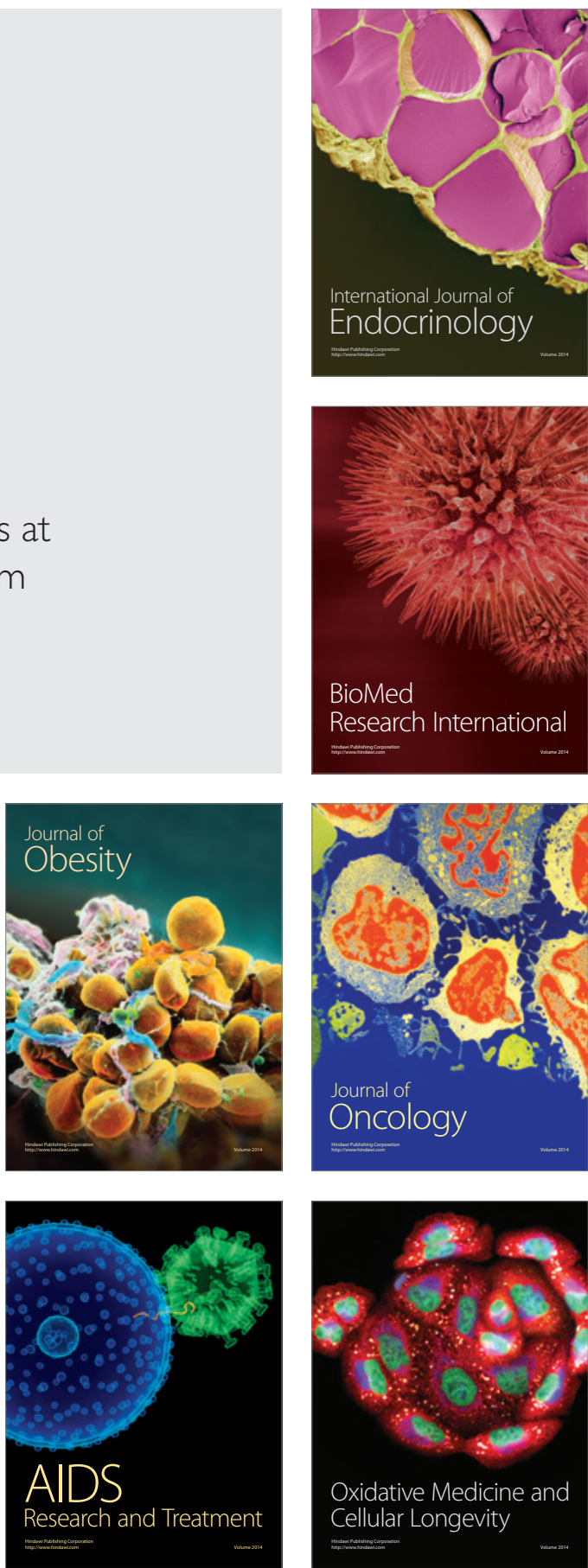